\title{
DETERMINAÇÃO DE COEFICIENTES DE DIFUSÃO EM HIDROGEL DE CELULOSE BACTERIANA
}

\author{
T. C.ANTONIO ${ }^{1}$, G.COLLA ${ }^{1}$, A. C. B. STREB $^{1}$ e L. M. PORTO ${ }^{1}$ \\ ${ }^{1}$ Universidade Federal de Santa Catarina, \\ Departamento de Engenharia Química e Engenharia de Alimentos \\ E-mail para contato: \{tuane, guilherme_colla, carolina, luismar\}@intelab.ufsc.br
}

\begin{abstract}
RESUMO - A celulose bacteriana (CB) é um biopolímero biocompatível e atóxico, características essas que o tornam um biomaterial promissor na área da saúde; devido a suas propriedades apresenta uma ampla gama de aplicações em engenharia tecidual e em sistemas de liberação de fármacos. Quando pretende-se desenvolver sistemas de absorção, liberação e eliminação de fluidos biológicos e fármacos é necessário a compreensão dos fenômenos de transferência de massa desses sistemas, sendo fundamental o conhecimento de parâmetros como o coeficiente de difusão do material estudado. Para tanto, no presente trabalho um sistema de câmara de difusão horizontal foi desenvolvido, onde verificou-se a transferência de massa de soluções de albumina de soro bovino (BSA), lisozima e vitamina B6, visando a determinação de parâmetros de transporte e interação em membranas de CB. O sistema de câmaras de difusão se constitui em duas câmaras interligadas por uma membrana de celulose bacteriana. Os parâmetros de transporte foram calculados a partir da resposta transiente. Os coeficientes de difusão obtidos para o BSA, lisozima e vitamina B6 foram respectivamente de $1,22 \times 10^{-9}, 5,82 \times 10^{-9}, 3,94 \times 10^{-7} \mathrm{~cm}^{2} \cdot \mathrm{s}^{-1}$.
\end{abstract}

\section{INTRODUÇÃO}

O estudo hidrodinâmico do comportamento de espécies individuais em solução diluída perante matrizes de biopolímeros vem ganhando uma crescente importância, utilizando-se como parâmetros de análise o tamanho e forma molecular do objeto de estudo (Phillies, 1985). A celulose bacteriana se destaca por ser um biopolímero de fácil manuseio, controle e manipulação. Em contraste com algumas membranas sintéticas, membranas de celulose bacteriana apresentam uma elevada resistência a produtos químicos corrosivos, mas são biodegradáveis e, portanto, consideradas um material ecológico (Bodhibukkanaet al., 2006).

O comportamento de solutos em hidrogéis tem sido explicado em termos de redução do volume de hidrogel livre. Membranas mais "fechadas" oferecem uma maior resistência à transferência de massa (Habert et al., 2003), e influências de arraste e obstruções hidrodinâmicas do soluto também contribuem para a resistência à passagem do soluto(Amsden, 1998).

Os parâmetros de transporte de massa e morfologia da membrana são pontos focais nos esforços para se estabelecer e controlar o microambiente ao se utilizar sistemas de celulose bacteriana (Sokolnickiet al., 2006) com aplicações biomédicas. A difusão caracteriza-se como a transferência de massa de uma substância através do material por diferença de potencial químico ou concentração (Térmica, 2009). Portanto, para interpretar gradientes difusivos em filmes finos 
medidos quantitativamente em termos das espécies presentes na solução, é necessário conhecer com precisão os coeficientes de difusão de cada espécie dentro do gel (Scallyet al., 2006).

A técnica de difusão em filmes finos por gradiente de concentração (DGT) baseia-se na $1^{\mathrm{a}}$ Lei de Difusão de Fick, que descreve a difusão do soluto em um meio no qual inicialmente não existe equilíbrio químico. Nesta situação estabelece-se um gradiente de concentração, produzindo um fluxo de moléculas que tendem a homogeneizar a solução e uniformizar a concentração (Colaço et al., 2012).

Neste contexto, a importância deste estudo se dá pelo fato de que substâncias confinadas em interfaces sólido-líquido podem influenciar no comportamento de diversos sistemas biológicos e biomédicos (Tilton et al., 1990). Por exemplo, a estrutura e a atividade de camadas de proteína adsorvida pode determinar a interação entre cultura celular e substratos sólidos, a biocompatibilidade de materiais naturais e sintéticos, e a viabilidade de imunoensaios de fase sólida (van den Wildenberg et al., 2011).

\section{METODOLOGIA}

\subsection{Produção das membranas de celulose bacteriana}

Neste trabalho, bactéria Gluconacetobacter hanseniifoi inoculada a 20\% (v/v) em placas de 24 poços, com volume de $1 \mathrm{~mL}$ por poço, contendo meio manitol(composição: $25 \mathrm{~g} \cdot \mathrm{L}^{-1}$ de manitol, $5 \mathrm{~g} \cdot \mathrm{L}^{-1}$ de peptona e $3 \mathrm{~g} \cdot \mathrm{L}^{-1}$ de extrato de levedura). A bactéria foi cultivada durante 7 dias a $25^{\circ} \mathrm{C}$ e cultivo estático; após este período as membranas formadas foram retiradas e deixadas em uma solução de hidróxido de sódio $0,1 \mathrm{M}$ durante 24 horas e, posteriormente, lavadas em água destilada, ajustando-se o pH para 7,0.Após esse procedimento as membranas foram esterilizada sem autoclave a $121^{\circ} \mathrm{C}, 1,2 \mathrm{kgf} \cdot \mathrm{cm}^{-2}$, durante $20 \mathrm{~min}$.

\subsection{Montagem das câmaras de difusão}

Três moléculas representativas foram utilizadas para medir a difusão passiva através das membranas: lisozima, albumina de soro bovino (BSA) e 4,5-di(hidroximetil)-2-metilpiridin-3-ol (vitamina B6) foram escolhidos pela sua variação de massa molar, carga superficial efetiva e diâmetro hidrodinâmico, bem como os seus vários graus de interação com a membrana.

Foi utilizado um sistema de tubos Falcon de $50 \mathrm{~mL}$, adaptados para servirem como câmaras de difusão, ligados por uma membrana de celulose bacteriana, o material no qual se pretende medir as difusividades, como mostra a Figura 1.

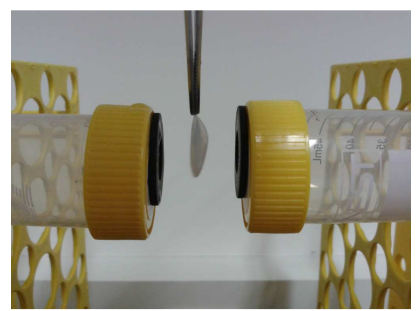

Figura 1 - Câmaras de difusão e membrana de celulose bacteriana. 
Utilizou-se tampão acetato com pH 7,0, previamente preparado, nas câmaras receptoras. Nas câmaras doadoras foram utilizadas soluções de vitamina B6, lisozima e BSA nas concentrações de $0,16 \mathrm{mg} \cdot \mathrm{mL}^{-1}, 1 \mathrm{mg} \cdot \mathrm{mL}^{-1}$ e $2 \mathrm{mg} \cdot \mathrm{mL}^{-1}$, respectivamente; as soluções foram diluídas em tampão acetato com $\mathrm{pH} 7,0$.

\subsection{Método analítico e cálculos}

A microestrutura das membranas de celulose bacteriana foi observada através de Microscopia Eletrônica de Varredura (MEV); para tal, as membranas de CB foram liofilizadas, após o que foram fixadas em fitas de carbono aderidas a suportes de alumínio (stubs) e, metalizadas com ouro para visualização da superfície superior e inferior. O equipamento utilizado foi um microscópio eletrônico de varredura JEOL JSM-6390LV.

Para o cálculo do coeficiente de difusão e da constante da câmera de difusão, amostras foram retiradas das duas câmaras, periodicamente, e lidas em um espectrofotômetro (Spectramaxplus 384 Molecular Devices), no comprimento de onda de 290nm, e correlacionadas com suas respectivas curvas de calibração.

Com base no modelo de Stokes (Equação 1 e 2) (Cussler, 2006), calculou-se o coeficiente de difusão através de membranas.

$$
\begin{gathered}
D=\frac{1}{\beta t} \ln \left[\frac{\left(c_{1}, \text { receptora }-c_{1}, \text { doadora }\right) \text { inicial }}{\left(c_{1}, \text { receptora }-c_{1}, \text { doadora }\right) \text { tempo } t}\right] \text { Equação } 1 \\
\beta=\frac{A}{l}\left(\frac{1}{V_{\text {doadora }}}+\frac{1}{V_{\text {receptora }}}\right) \text { Equação } 2
\end{gathered}
$$

Nas equações acima, $D$ é o coeficiente de difusão, $\beta$ é a constante da câmera de difusão, $t$ é o tempo e $c_{1}$ é a concentração de soluto. É necessário obter o parâmetro $\beta$ através da área de difusão $(A)$, a espessura efetiva da membrana $(l)$ e o volume das câmaras $(V)$.

\section{RESULTADOS}

A Figura 2 apresenta a microestrutura das membranas de celulose bacteriana utilizadas nos ensaios, tanto da superfície superior (região densa de nanofibras de celulose) quanto da inferior (região porosa de nanofibras de celulose), respectivamente, observada utilizando-se imagens de Microscopia Eletrônica de Varredura (MEV). 


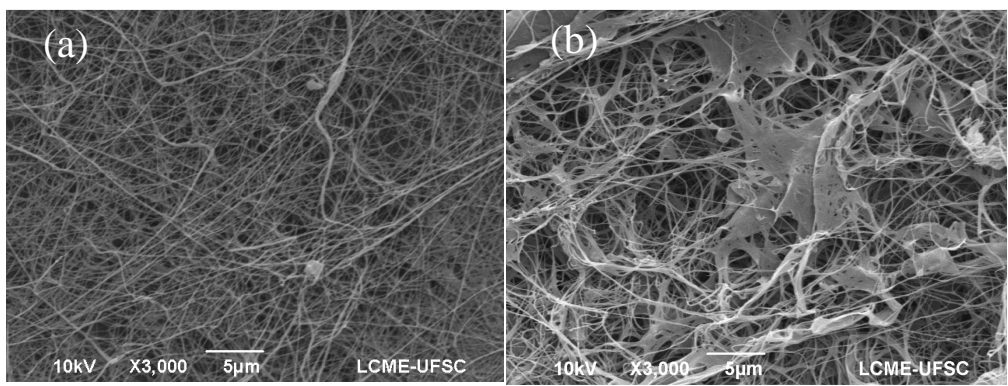

Figura 2 - Análise de Microscopia Eletrônica de Varredura (MEV) das membranas de celulose bacteriana utilizadas, (a) superfície superior e (b) superfície inferior.

O transporte de solutos pode ser classificado através de dois mecanismos: o mecanismo de poros e o mecanismo de absorção. No mecanismo de poros, presume-se que o soluto se difunde através dos fluidos pelos canais no interior da membrana, enquanto que no mecanismo de absorção, o soluto está adsorvido na matriz de membrana e difunde-se através desta ou ao longo de suas fibras (Lebrun et al., 1994). A Figura 2 (a) e (b) demonstra que as membranas de CB utilizadas apresentam uma estrutura porosa, em que a estrutura não apresenta nenhum poro cilíndrico definido; a quantidade e a divisão dos poros sugerem que o material apresenta caminhos tortuosos de dimensões diversas, que se apresentam como obstáculos internos à difusão das moléculas,podendo-se assim considerar que o transporte ocorre principalmente através do mecanismo de poros.Um parâmetro que represente a relação entre o tamanho do soluto para o tamanho do poro é comumente utilizado;entretanto, não foi possível definir a geometria dos poros das membranas de celulose bacteriana,não sendo aplicável este parâmetro ao sistema.

O comportamento das amostras até o ponto de equilíbrio (entre as câmaras) pode ser visualizado na Figura 3. Estes resultados representam as concentrações nas câmaras doadoras e receptoras para as três moléculas estudadas. Os pontos marcados na Figura 3 (a), (b) e (c) mostram a tendência da difusão.

Da Figura 4 (a) observam-se fases distintas durante o processo; os pontos iniciais mostram uma maior velocidade com relação aos demais pontos, uma vez que as substâncias começam a preencher os poros das membranas, dificultando a passagem do soluto. Proteínas e enzimas, em geral muito maiores do que moléculas esféricas (vitamina B), têm migração mais lenta através da rede de fibras devido a interações, imobilização temporária e/ou resistência devido a trechos mais estreitos(Sokolnicki et al., 2006).

A Tabela 1 mostra que quanto maior o tamanho da molécula menor será o coeficiente de difusão, como obviamente esperado. A vitamina B6 apresenta uma massa molar de 169,18 Da sendo o coeficiente obtido de $3,94 \times 10^{-7} \mathrm{~cm}^{2} \cdot \mathrm{s}^{-1}$. Comparando-se o BSA com a vitamina B6, o mesmo possui uma massa molar 390 vezes maior e seu coeficiente de difusividade obtido foi 323 vezes menor.

O processo de difusão testado foi o de difusão passiva, e moléculas de tamanho menor apresentaram uma maior facilidade em se difundir pelas fibras da matriz polimérica (Sokolnicki et al.,2006), utilizando BSA, lisozima e vitamina B12, obtiveram, respectivamente, os coeficientes de difusão de $0,59 \times 10^{-6}, 1,04 \times 10^{-6}$ e $3,79 \times 10^{-6} \mathrm{~cm}^{2} \cdot \mathrm{s}^{-1}$ em condições de difusão dinâmica. Pode-se observar que apesar dos processos de difusão serem distintos, há uma grande consistência entre ambos os estudos. 
(a)

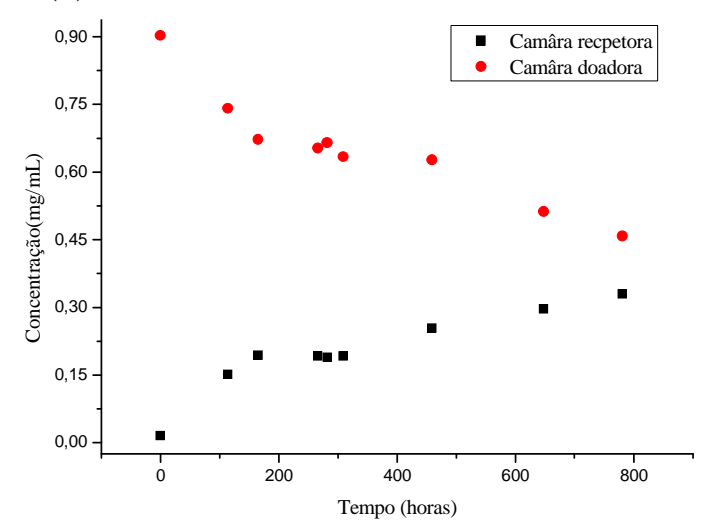

(b)

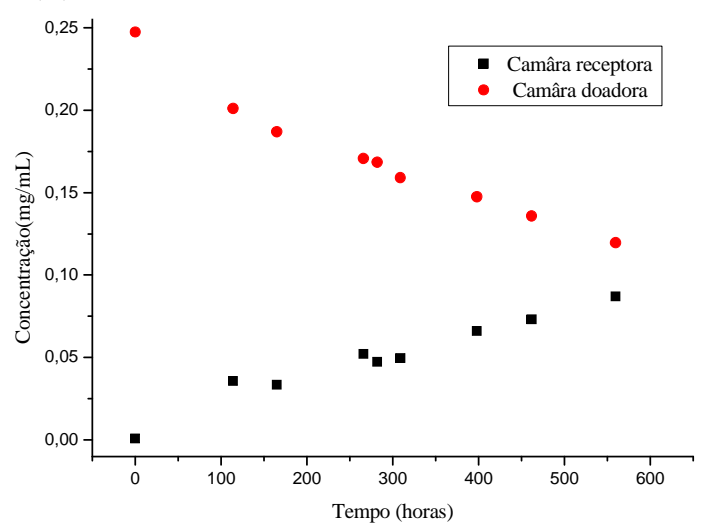

(c)

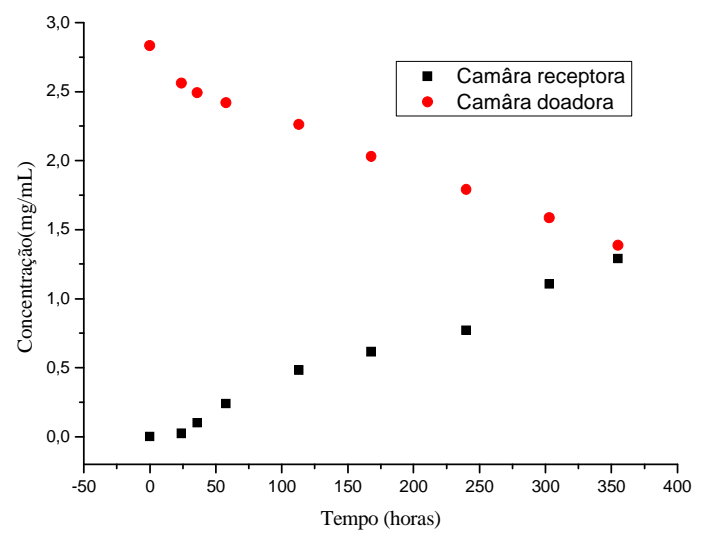

Figura 3 - Evolução da concentração em função do tempo para difusão de (a) lisozima, (b) BSA e (c) Vitamina B6, em hidrogel de celulose bacteriana.

Com os valores de concentração obtidos em cada caso calculou-se $D$ e o parâmetro $\beta$, sendo estes apresentados na Tabela 1.

Tabela 1 - Coeficiente de difusão utilizando o Método Célula de Diafragma de Stokes.

\begin{tabular}{c|c|c|c}
\hline Amostra & $\mathbf{M M}(\mathbf{D a})$ & $\boldsymbol{\beta}\left(\mathbf{c m}^{-2}\right)$ & $\boldsymbol{D}\left(\mathbf{c m}^{2} \cdot \mathbf{s}^{-\mathbf{1}}\right)$ \\
\hline BSA & 66000 & & $1,22 \times 10^{-9}$ \\
Lisozima & 14100 & 0,791 & $5,82 \times 10^{-9}$ \\
Vitamina B6 & 169,18 & & $3,94 \times 10^{-7}$ \\
\hline
\end{tabular}




\section{CONCLUSÕES}

O presente estudo determinou os coeficientes de difusão de BSA, lisozima e vitamina B6, em hidrogéis de celulose bacteriana, na forma de membranas. Esses parâmetros são importantes para o desenvolvimento de materiais para engenharia de tecidos, sobretudo porque permitem avaliar a viabilidade da utilização de celulose bacteriana como uma matriz de suporte para células ou tecidos engenheirados. O objetivo é melhorar as propriedades de barreira (para proteção ou transporte), quando o controle do microambiente for essencial para a viabilidade e um comportamento operacional normal, uma vez que redes de fibras abertas são ideais para a imobilização de compostos capazes de reagir com espécies em difusão, enquanto permitem a passagem de nutrientes e proteínas com ligeiro retardo.Novas utilizações para a celulose bacteriana podem também incluir sistemas de membranas para o crescimento e/ou regeneração de novos tecidos, bem como terapias à base de células e entrega controlada de fármacos.

\section{REFERÊNCIAS}

AMSDEN, B. Solute diffusion within hydrogels. Mechanisms and models. Macromolecules, v. 31, n. 23, p. 8382-8395, 1998.

BODHIBUKKANA, C.; SRICHANA, T.; KAEWNOPPARAT, S.; TANGTHONG, N.; BOUKING, P.; MARTIN, G. P.; SUEDEE, R. Composite membrane of bacterially-derived cellulose and molecularly imprinted polymer for use as a transdermal enantioselective controlledrelease system of racemic propranolol. J. Control. Release., v. 113, n. 1, p. 43-56, 2006.

COLAÇO, C. D.; YABUKI, L. N. M.; ALCÂNTARA, A. L.; MENEGÁRIO, A. A. Coeficientes de difusão de metais em materiais não convencionais (agarose e acetato de celulose) usados na técnica de difusão em filmes finos por gradientes de concentração. Quim. Nova., v. 35, n. 7, p. 1360-1364, 2012.

CUSSLER, E. L. Diffusion: Mass Transfer in Fluid Systems,3nd edition. Cambridge University Press, New York, 580p, 2006.

HABERT, A.; BORGES C.; NOBREGAR, R.Escola Piloto em Engenharia Química: Processos deSeparação com Membranas. Programa de Engenharia Química, COPPE/UFRJ, Rio de Janeiro, RJ, Brasil, 2003.

LEBRUN, L.; JUNTER, G.A. Diffusion of dextran through microporous membrane filters. $J$. Membrane. Sci., v. 88, n. 2, p. 253-261, 1994.

PHILLIES, G. D. Diffusion of bovine serum albumin in a neutral polymer solution. Biopolymers, v. 24, n. 2, p. 379-86, Feb 1985.

SCALLY, S.; DAVISON, W.; ZHANG, H. Diffusion coefficients of metals and metal complexes in hydrogels used in diffusive gradients in thin films. Anal. Chim. Acta., v. 558, n. 1, p. 222-229, 2006.

SOKOLNICKI, A. M.; FISHER, R. J.; HARRAH, T. P.; KAPLAN, D. L. Permeability of bacterial cellulose membranes. J. Membrane. Sci., v. 272, n. 1, p. 15-27, 2006.

TÉRMICA, O. E. Métodos para Determinação do Coeficiente de Difusão de COVs em Materiais de Construção. Universidade do Porto, 2009. 
TILTON, R. D.; GAST, A. P.; ROBERTSON, C. R. Surface diffusion of interacting proteins. Effect of concentration on the lateral mobility of adsorbed bovine serum albumin. Biophys. J., v. 58, n. 5, p. 1321-6, Nov 1990.

VAN DEN WILDENBERG, S. M.; BOLLEN, Y. J.; PETERMAN, E. J. How to quantify protein diffusion in the bacterial membrane. Biopolymers, v. 95, n. 5, p. 312-21, May 2011. 